\title{
The Effect of Local Delivery Doxycycline and Alendronate on Bone Repair
}

\author{
Pedro Henrique Justino Oliveira Limirio, ${ }^{1,2,4}$ Flaviana Soares Rocha, ${ }^{3}$ Jonas Dantas Batista, ${ }^{3}$ \\ João César Guimarães-Henriques, ${ }^{3}$ Geraldo Batista de Melo, ${ }^{3}$ and Paula Dechichi ${ }^{3}$
}

\begin{abstract}
Received 16 June 2015; accepted 2 September 2015; published online 17 September 2015
Abstract. The aim of the present study was to investigate the local effect of $10 \%$ doxycycline and $1 \%$ alendronate combined with poly(lactic-co-glycolic acid) (PLGA) on bone repair. Thirty rats were divided into three groups, as follows: control group (CG), drug group (DG), and vehicle-PLGA group (VG). Bone defect was created in the right femur and filled with the following: blood clot (CG); PLGA gel, 10\% doxycycline and $1 \%$ alendronate (DG); or vehicle-PLGA (VG). The animals were euthanized 7 or 15 days after surgery. Bone density, bone matrix and number of osteoclasts were quantified. At 7 days, the findings showed increased density in DG $(177.75 \pm 76.5)$ compared with CG $(80.37 \pm 27.4)$, but no difference compared with VG (147.1 \pm 41.5$)$; no statistical difference in bone neoformation CG $(25.6 \pm 4.8)$, VG (27.8 \pm 4$)$, and DG (18.9 \pm 7.8$)$; and decrease osteoclasts in DG $(4.6 \pm 1.9)$ compared with CG $(26.7 \pm 7.4)$ and VG (17.3 \pm 2.7$)$. At 15 days, DG (405.1 \pm 63.1$)$ presented higher density than CG (213.2 \pm 60.9$)$ and VG $(283.4 \pm 85.8)$; there was a significant increase in percentage of bone neoformation in DG $(31.5 \pm 4.2)$ compared with CG $(23 \pm 4)$, but no difference compared with VG $(25.1 \pm 2.9)$. There was a decreased

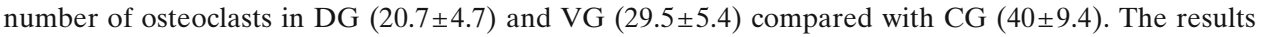
suggest that the association of $10 \%$ doxycycline and $1 \%$ alendronate with PLGA-accelerated bone repair.
\end{abstract}

KEY WORDS: alendronate; bone repair; doxycycline.

\section{INTRODUCTION}

Bone repair and reconstruction of large defects are challenges to clinical therapies in several areas of medicine. Bone tissue regeneration is a complex sequence of events that begins with the recruitment, attachment, and proliferation of progenitor cells, followed by cell differentiation into phenotypes capable of restoring the damaged tissue (1).

At present, bone repair strategies have been explored, using factors that stimulate osteogenesis (2), such as bone morphogenetic protein 2 (BMP-2) (3), basic fibroblast growth factor (b-FGF) (4), platelet-rich plasma (PRP) (5), transforming growth factor-beta 1 (TGF- $\beta 1$ ) (6), and vascular endothelial growth factor (VEGF) (7). Recent investigations have shown that different classes of drugs, such as bisphosphonates, tetracyclines, and their combination, stimulate osteogenesis when their use was evaluated with regard to alveolar bone loss in periodontitis (8-10), healing of bone defects (1) and in vitro cell culture $(11,12)$.

\footnotetext{
$\overline{{ }^{1} \text { Integrated Dental Clinic Program, School of Dentistry, University of }}$ Uberlândia, Minas Gerais, Brazil.

${ }^{2}$ Departamento de Cirurgia e Traumatologia Buco-Maxilo-Facial, Bairro Umuarama, Avenida Pará s/nº, Campus Umuarama, Bloco 4T, Uberlândia, Minas Gerais, Brazil38.400-902.

${ }^{3}$ University of Uberlândia, Minas Gerais, Brazil.

${ }^{4}$ To whom correspondence should be addressed. (e-mail: pedro_hjlo@hotmail.com)
}

Bisphosphonates have an anabolic effect on osteoblasts (13-16), improving proliferation and maturation $(11,17)$, inhibiting apoptosis (16), and considering the aforementioned actions, and could result in increased bone formation $(11,17)$. Bisphosphonates are well-known inhibitors of osteoclastic activity and are widely used to treat osteoporosis; among them, alendronate is one of the most potent anti-osteoporotic agents known (18). Studies have shown that locally delivered alendronate has an effect on increased bone repair in a critical-sized calvarial defect (19) and peri-implant bone formation (20) and associated with bone allografts (21). Moreover, alendronate enhances alkaline phosphatase (ALP) activity and bone neoformation (19).

Semi-synthetic tetracyclines, such as the administration of doxycycline in either local or systemic sub-antimicrobial doses, have been studied to minimize host tissue breakdown. In periodontal surgery, Doxycycline has been shown to improve wound healing, to increase osteogenic mediators, and to reduce collagenase (22). Recently, the benefits of doxycycline as an osteogenic agent was observed on the surface of bone implants (23), in healing of oral infrabony defects (24) and osteoclastogenesis downregulation in vitro (25).

Poly(lactic-co-glycolic acid) (PLGA) has been used as a delivery vehicle for almost all types of antibiotics, due to its tunable degradation profile and biocompatible degradation products (26). Several studies have reported the release of antibiotics from PLGA to occur over the span of weeks to months $(27,28)$. Antibiotic-loaded PLGA has also been incorporated into tissue engineering scaffolds for the purpose of 
mitigating infection, and release has been reported to occur over 8 weeks in vitro (27).

In the present study, it was hypothesized that association of the anabolic properties of alendronate (12) with the antibiotic and anti-proteolytic properties of doxycycline (29) combined with the delivery system of PLGA $(30,31)$ would increase bone neoformation and accelerate bone repair. The null hypothesis tested was that local delivery of $10 \%$ doxycycline and $1 \%$ alendronate in PLGA would not affect the repair of experimental bone defects in rats at 7 and 15 days.

\section{MATERIAL AND METHODS}

\section{Experimental Procedure}

The sample consisted of 30 healthy male Wistar rats (Rattus norvegicus), weighing 250 to $300 \mathrm{~g}$. The animals were kept in cages, in a 12-h:12-h light-dark cycle, and controlled temperature conditions $\left(22 \pm 2^{\circ} \mathrm{C}\right)$, with standard food and water ad libitum. This study was previously approved by the Science and Ethics Committee from Federal University of Uberlândia, Brazil, Protocol 022/12, and was performed in accordance with the Brazilian College for Animal Experimentation (COBEA). The animals were randomly divided into three groups, with each group being composed of five animals, as follows: control group (CG), Clot; drug group (DG), 10\% doxycycline and 1\% alendronate in PLGA; vehicle group (VG), only PLGA. The animals were euthanized after 7 or 15 days.

All animals were submitted to osteotomy in the right femur to create a bone defect, after being anesthetized with intraperitoneal injection of $2 \%$ ketamine ratio $100 \mathrm{mg} / \mathrm{kg}$ and $10 \%$ xylazine hydrochloride ratio $3 \mathrm{mg} / \mathrm{kg}$. They were placed in the left lateral decubitus position, and access to bone was achieved by making a continuous longitudinal incision of $2 \mathrm{~cm}$, exposing the mid-diaphysis. A standardized 2.3-mm diameter osteotomy was performed with a round bur under saline solution irrigation. The drilling depth limit was disruption of the femoral cortical bone. In CG, the defect was filled only with blood clot; in DG, the defect was filled with $10 \mu \mathrm{L}$ of gel composed of $10 \%(1000 \mu \mathrm{g})$ doxycycline (Neo-química, Anápolis, MG, Brazil) and 1\% (100 $\mu \mathrm{g})$, alendronate (Neoquímica, Anápolis, MG, Brazil) in PLGA, and VG the defect was filled with $10 \mu \mathrm{l}$ of vehicle-PLGA (lactide/glycolide ratio 50/50, Mw $=40,000-75,000)$. The drugs and PLGA were mixed with Misonix Sonicator (Microson XL 2000, Misonix Incorporated, Farmingdale, NY, USA). After this, soft tissues were repositioned and suturing was performed in muscle and cutaneous layers using nylon 4-0. After 7 and 15 days, the animals were euthanized. The femurs were removed, fixed in $10 \%$ phosphate buffer formaldehyde solution for $48 \mathrm{~h}$, and kept in phosphate buffer solution until analysis was performed.

\section{Computed Tomographic Analysis}

The femurs were positioned perpendicular to the basal surface and scanned in a Cone-Beam 3D scanner (Gendex, GX-CB500-ICAT) at $7 \mathrm{~mA}, 120 \mathrm{kvp}$, and 0.125 voxel resolution. From each specimen, three tomographic images of the region of interest (ROI) within the bone defect were selected. In these images, the bone defect was delimited with a rectangle. Two squares measuring $0.1 \mathrm{~mm}^{2}$ were marked in the cortical and medullary region to serve as maximum and minimum reference values achieved in the same image. In addition, the blood, drugs and vehicle-PLGA were placed in Eppendorf tubes and were scanned to obtain the individual radiodensity. The Hounsfield scale of regions and materials was obtained using specific software (i-CAT® Vision, Imaging Sciences International, Penn Road, Hatfield, PA).

\section{Histologic and Histomorphometric Analysis}

After computed tomographic (CT) analysis, the specimens were decalcified in $10 \%$ EDTA, dehydrated with series of graded ethanol and embedded in paraffin. The $5-\mu \mathrm{m}$ longitudinal histological sections obtained were stained with hematoxylin and eosine (HE) and Mallory trichrome. For quantifying bone matrix neoformation, histological images of the bone defect were captured, using a binocular microscope Nikon Eclipse E2000 (Nikon®, Nikon do Brasil, São Paulo, Brazil) coupled to a Moticam Pro 252B camera (Motic ${ }^{\circledR}$, British Columbia, Canada) and the software Motic Live Imaging Module (Motic $\AA$, British Columbia, Canada). The screen shots were merged, soft tissue was erased using Photoshop CS6 software (Adobe ${ }^{\circledR}$, Adobe System Inc., San Jose, CA/USA), and finally, they were converted into binary images with HL Image 2005++ (Western Vision, Salt Lake City, UT, USA). The ROI was delineated with four straight lines from the defect of the cortical bone up to the internal surface to the opposite cortical. The percentage of bone matrix neoformation within the ROI was calculated with HL Image 2005.

Of the HE-stained specimens, 180 histological images of ROI were analyzed in each group, of every period. The images were obtained using Leica ${ }^{\circledR}$ DM2500 M Microscope (Leica Microsystems ${ }^{\circledR}$, Buffalo Grove, Illinois, USA) $\geq$. Two blinded examiners counted all the osteoclasts present in the ROI considering cells that presented with greater that or equal to two nuclei, associated with the bone resorption surface (32). Any disagreements between the two examiners were resolved by a third examiner. The inter-reviewer reliability of data extraction was calculated by determining the percentage of agreement and the correlation coefficient (kappa, $5 \%$ level of significance).

\section{Statistical Analysis}

Analysis was performed using statistical software GraphPad Prism (version 5.0 for Windows, San Diego, CA, USA). The results obtained were submitted to the ShapiroWilk normality test and Two-Way Anova followed by the Tukey test. Differences were considered statistically significant when $\alpha<0.05$.

\section{RESULTS}

After the surgery, all animals showed normal behavior; they lost no weight and wound healing progressed without any signs of infection.

CT analysis showed there was no significant difference in the bone radiodensity at the cortical (Fig. 1a) and medullar reference between the femurs among the groups (Fig. 1b). 


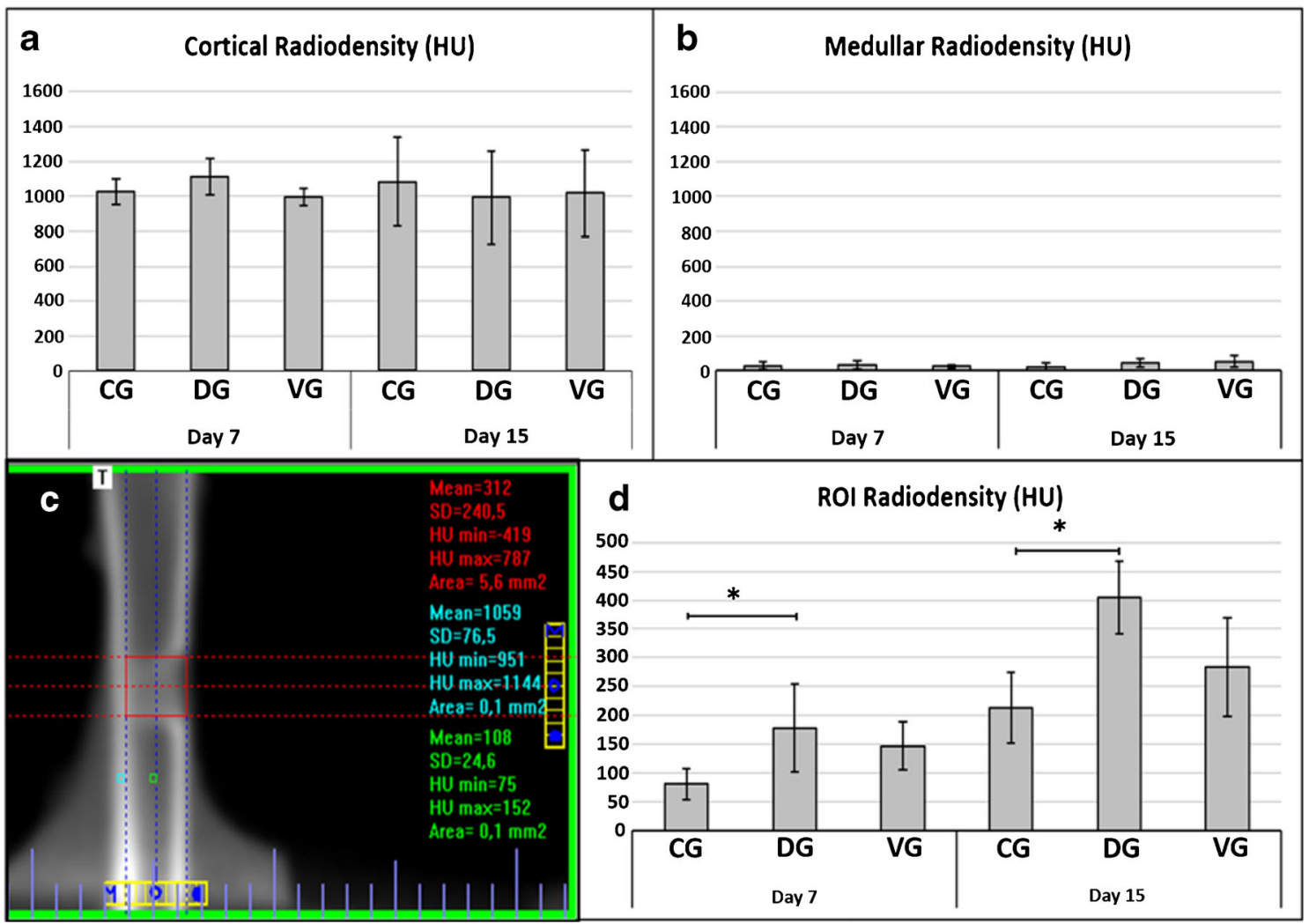

Fig. 1. Bone radiodensity references in cortical $\mathbf{a}$ and medullar $\mathbf{b}$ areas. Computed tomographic image demonstrating the region of interest (ROI) delineation $\mathbf{c}$. Bone radiodensity in ROI all evaluated groups $(\mathbf{d})\left({ }^{*} P<0.05\right)$

However, the ROI analysis showed increased density in DG (177.75 \pm 76.5$)$ compared with CG $(80.37 \pm 27.4)$, but no difference compared VG $(147.1 \pm 41.5)$ with DG and CG at 7 days. After 15 days, DG $(405.1 \pm 63.1)$ presented higher density than CG (213.2 \pm 60.9$)$ and VG $(283.4 \pm 85.8)$ (Fig. 1d) $(P<0.05)$.

Histologic analysis in the photomicrograph of femur longitudinal section at 7 days showed similar bone healing in $\mathrm{CG}$ and VG. In these groups, the ROI was almost filled by primary bone (PB) and periosteum was reasonably well cellularized with many fusiform cells between collagens fibers. Around collagen fibers, granulation tissue (GT) and blastema regeneration were observed, characterized by intense proliferation and differentiation of mesenchymal cells. In DG, the ROI was almost totally occupied by blood clots (BC) with large areas of fibrin network. At the periphery, there was chronic inflammatory infiltration with giant cells, and dilated vessels with many leukocytes. Around the inflammation, there was granulation tissue (GT) and incipient primary bone (PB). The periosteum was cellularized with few fibers between the cells (Fig. 2).

At 15 days, in $\mathrm{CG}$ and $\mathrm{VG}$, histological analysis showed ROI filled by primary bone (PB) with thinner trabecular bone
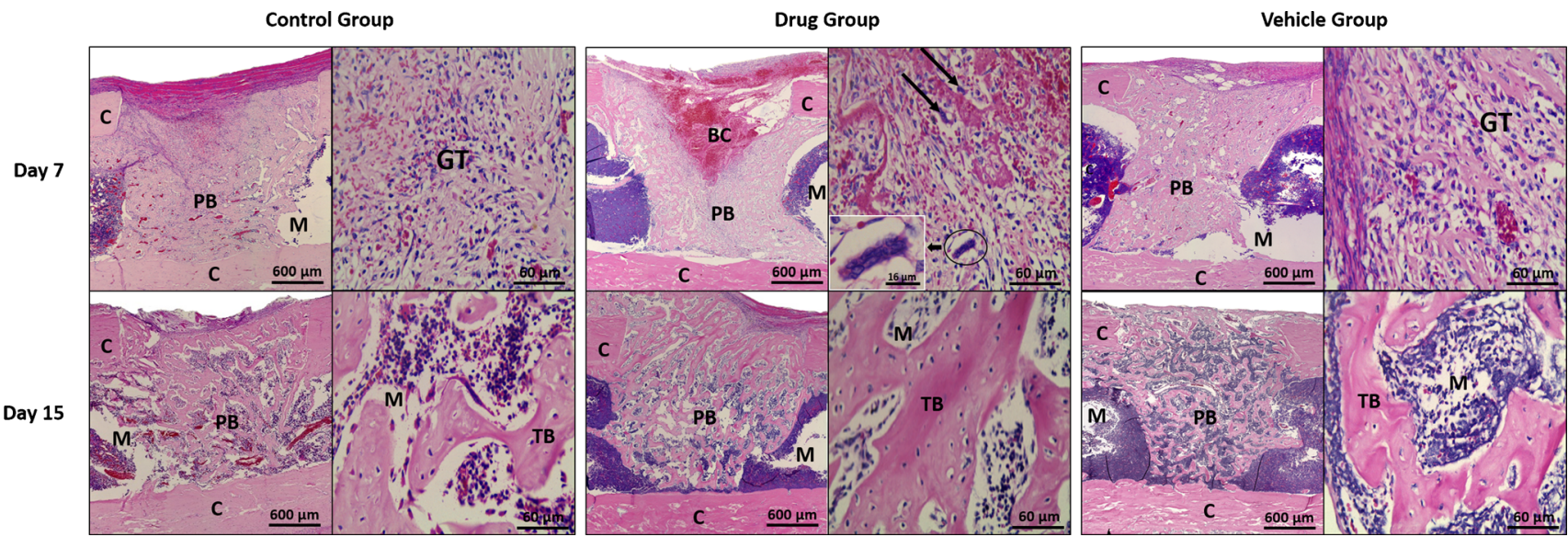

Fig. 2. Photomicrograph of femur longitudinal section of all groups. Cortical $(C)$. Medullary tissue $(M)$. Primary bone $(P B)$. Granulation tissue $(G T)$. Trabecular bone $(T B)$. Blood cot $(B C)$. Giant cell (arrow). Hematoxylin and eosin 


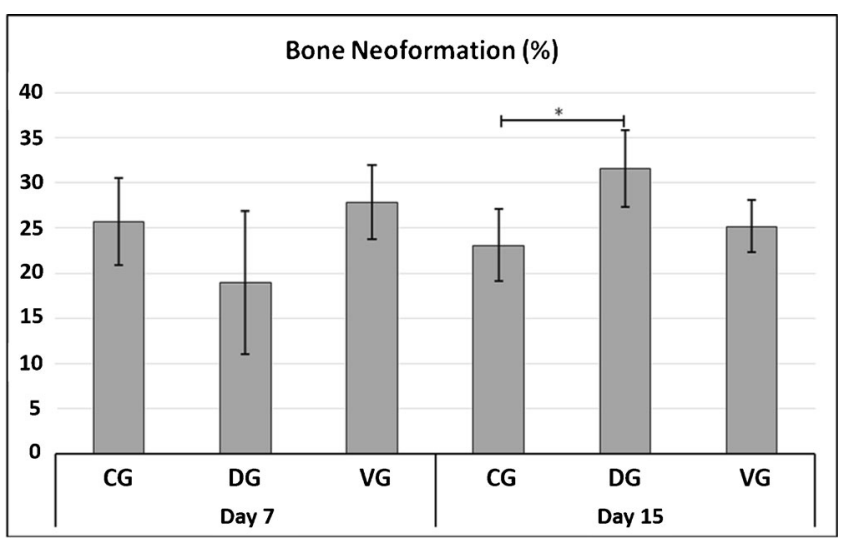

Fig. 3. Percentage of bone neoformation in CG (control group), DG (drug group), and VG (vehicle group) at 7 and 15 days $(* P<0.05)$

(TB) and large spaces between them, filled with medullary tissue (M). DG showed bone neoformation similar to $\mathrm{CG}$ and VG. However, in DG, primary bone (PB) tissue filled the defect area and extended largely into the medullary channel; also, the trabecular bone (TB) were thicker, especially in comparison with CG (Fig. 2).

The histomorphometric analysis at 7 days showed no statistical difference between the groups CG $(25.6 \pm 4.8), \mathrm{VG}$ $(27.8 \pm 4)$, and DG $(18.9 \pm 7.8)$. However, statistical analysis showed a significant increase in the percentage of bone neoformation in DG $(31.5 \pm 4.2)$ when compared with CG $(23 \pm 4)$, but no difference when VG $(25.1 \pm 2.9)$ was compared with DG and $\mathrm{CG}$ at 15 days $(P<0.05)$ (Fig. 3).

The number of osteoclasts in DG $(4.6 \pm 1.9)$ decreased compared with CG $(26.7 \pm 7.4)$ and VG $(17.3 \pm 2.7)$ at 7 days. There was an increased number of osteoclasts between CG $(40 \pm 9.4)$ compared with DG $(20.7 \pm 4.7)$ and VG $(29.5 \pm 5.4)$ at 15 days $(P<0.05)$ (Fig. 4). Agreement with kappa value $=0.89$ was obtained between the examiners about the number of osteoclasts.

\section{DISCUSSION}

The null hypothesis was rejected. The local delivery of $10 \%$ doxycycline and $1 \%$ alendronate gel affected the repair of experimental bone defects in rats at seven and fifteen days. Bone repair, a challenge in areas of medicine, is a complex process involving the action of systemic and locally produced growth factors, hormones, and vitamins and a delicate balance between osteoblasts and osteoclasts (33).

In the present study, the association between alendronate, doxycycline and PLGA (DG) showed an increase in the percentage of bone neoformation at fifteen days. This result might be attributable to the anti-collagenolytic effect of doxycycline, which enhances the bone-forming ability via osteoblast cell chemotaxis and reduces bone resorption via osteoclasts (34). In vivo periodontal studies have shown that combined therapy with alendronate and/or doxycycline leads to a reduction in hard tissue destruction, inhibition and down-regulation of matrix metalloproteinase $(8,9)$.

The decrease osteoclasts in DG could be due to the effect of RANKL down-regulation (35) osteoclast inhibition by alendronate $(13-15,18)$. Moreover, in order to inhibit bone resorption by osteoclasts, bisphosphonates also have an anabolic effect on osteoblasts (36). Studies have shown that numerous bisphosphonates (olpadronate, pamidronate, etidronate) induced osteoblast proliferation. Im et al. (11) investigated the effects of alendronate and risedronate on primary human trabecular bone cell cultures, in MG-63 osteoblast-like cell lines, and found that bisphosphonates promoted osteoblast proliferation and maturation, as shown by increased cell numbers and the enhanced expression of bone morphogenetic protein BMP-2, type I collagen, and osteocalcin.

The chronic inflammatory infiltration with multinucleated giant cells at 7 days found in DG could be due to the low $\mathrm{pH}(3,7)$ of the drug. The treatment with biomaterials was shown to be immunogenic for tissue in some studies, and the main etiological mechanism was the decrease in local $\mathrm{pH}$ and induction of host immunoreactivity (37).

Yaffe et al. (10) showed that local delivery of doxycycline with alendronate had no additive effect on alveolar bone loss. The author explained this result by the high concentration $(10 \%)$ of doxycycline in the preparation. However, the present study showed positive results with this concentration, probably due to the drug administration by the vehiclePLGA, which decreased the high concentration and reduced contact between the tissue and drugs $(30,31)$. The $10 \%$ of doxycycline has been used in several commercially available agents with positive results in bone formation (38) and alendronate can be applied topically in lower doses to locally inhibit bone resorption (39).

PLGA provides a wide range of advantages, such as a smaller particle size that facilitates penetration into the cells, higher entrapment efficiency for increased drug release, lower minimum

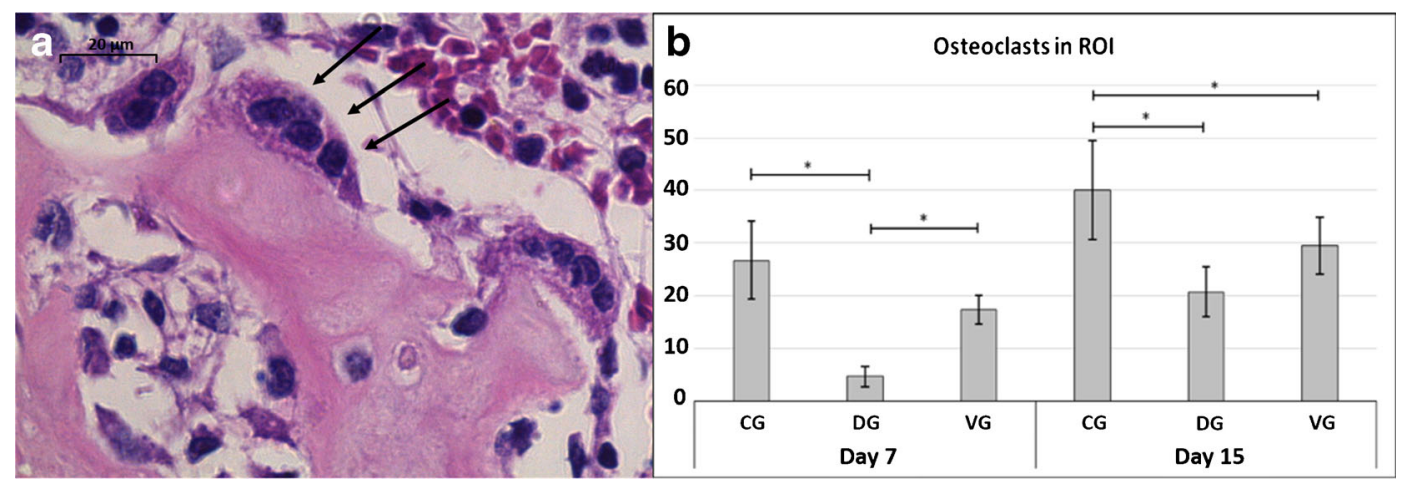

Fig. 4. a Morphologic osteoclast. b Number of osteoclasts in CG (control group), VG (vehicle group), and DG (drug group) at 7 and 15 days $(* P<0.05)$ 
inhibitory concentration, and minimum bacterial concentrations, meaning that a better antibacterial activity was achieved with a smaller amount of drug $(30,31)$. The present study provided evidence that a PLGA showed an interaction with bone repair when it was used as a filling material in bone defects. An in vitro study has shown that when in contact with a PLGA, human osteoblastic cells secrete extracellular matrix components such as collagen, fibronectin, and glycoproteins. Then, this organic extracellular matrix is used to support the osteoblast adhesion via receptors known as integrins (40).

CT showed that radiodensity increased at 7 and 15 days in DG. The results showed higher radiodensity in the DG group at 15 days, confirming the results found in the histomorphometric analyses. At 7 days, the results were controversial when compared with the histomorphometric analyses; however, a CT scan of the materials (blood, drugs, and vehicle) showed that in association with alendronate, doxycycline and PLGA had higher radiodensity than blood clots. Despite the limitation of the resolution of CT scans, which may have contributed to degradation of the grayscale fidelity of the final image displayed, it still provided important information about density in our study (41).

\section{CONCLUSION}

The results of this study suggest that the association of $10 \%$ doxycycline, $1 \%$ alendronate, and PLGA accelerates bone repair when compared with defects filled with blood clot or only vehiclePLGA. These finding could have significant clinical implications in bone reconstructive surgical procedures.

\section{ACKNOWLEDGMENTS}

This project was supported by the National Research Council (CNPq/Brazil) and Research Support Foundation of the State of Minas Gerais (FAPEMIG/Brazil).

Conflict of Interest The authors of this manuscript certify that they have no proprietary, financial, nor other personal interest of any nature or kind in any product, service, and/or company that was presented in this article, nor any conflict of interest.

Open Access This article is distributed under the terms of the Creative Commons Attribution 4.0 International License (http://creativecommons.org/licenses/by/4.0/), which permits unrestricted use, distribution, and reproduction in any medium, provided you give appropriate credit to the original author(s) and the source, provide a link to the Creative Commons license, and indicate if changes were made.

\section{REFERENCES}

1. Yaffe A, Kollerman R, Bahar H, Binderman I. The influence of alendronate on bone formation and resorption in a rat ectopic bone development model. J Periodontol. 2003;74(1):44-50. doi:10.1902/jop.2003.74.1.44.

2. Alvarez P, Hee CK, Solchaga L, Snel L, Kestler HK, Lynch SE, et al. Growth factors and craniofacial surgery. J Craniofac Surg. 2012;23(1):20-9. doi:10.1097/SCS.0b013e318240c6a8.

3. Alonso N, Tanikawa DY, Freitas Rda S, Canan Jr L, Ozawa TO, Rocha DL. Evaluation of maxillary alveolar reconstruction using a resorbable collagen sponge with recombinant human bone morphogenetic protein-2 in cleft lip and palate patients. Tissue Eng Part C Methods. 2010;16(5):1183-9. doi:10.1089/ten.TEC.2009.0824.

4. Hayashi K, Kubo T, Doi K, Tabata Y, Akagawa Y. Development of new drug delivery system for implant bone augmentation using a basic fibroblast growth factor-gelatin hydrogel complex. Dent Mater J. 2007;26(2):170-7.

5. Choo T, Marino V, Bartold PM. Effect of PDGF-BB and betatricalcium phosphate (beta-TCP) on bone formation around dental implants: a pilot study in sheep. Clin Oral Implants Res. 2013;24(2):158-66. doi:10.1111/j.1600-0501.2011.02345.x.

6. Hong L, Tabata Y, Miyamoto S, Yamamoto M, Yamada K, Hashimoto $\mathrm{N}$, et al. Bone regeneration at rabbit skull defects treated with transforming growth factor-beta1 incorporated into hydrogels with different levels of biodegradability. J Neurosurg. 2000;92(2):315-25. doi:10.3171/jns.2000.92.2.0315.

7. Minagawa T, Tabata Y, Oyama A, Furukawa H, Yamao T, Yamamoto Y. Controlled release of granulocyte colony-stimulating factor enhances osteoconductive and biodegradable properties of Beta-tricalcium phosphate in a rat calvarial defect model. Int $\mathbf{J}$ Biomater. 2014;2014:134521. doi:10.1155/2014/134521.

8. Buduneli E, Vardar-Sengul S, Buduneli N, Atilla G, Wahlgren J, Sorsa T. Matrix metalloproteinases, tissue inhibitor of matrix metalloproteinase-1, and laminin-5 gamma2 chain immunolocalization in gingival tissue of endotoxin-induced periodontitis in rats: effects of low-dose doxycycline and alendronate. J Periodontol. 2007;78(1):127-34. doi:10.1902/jop.2007.050451.

9. Ozdemir SP, Kurtis B, Tuter G, Bozkurt S, Gultekin SE, Senguven B, et al. Effects of low-dose doxycycline and bisphosphonate clodronate on alveolar bone loss and gingival levels of matrix metalloproteinase- 9 and interleukin-1beta in rats with diabetes: a histomorphometric and immunohistochemical study. J Periodontol. 2012;83(9):1172-82. doi:10.1902/jop.2012.110459.

10. Yaffe A, Herman A, Bahar H, Binderman I. Combined local application of tetracycline and bisphosphonate reduces alveolar bone resorption in rats. J Periodontol. 2003;74(7):1038-42. doi:10.1902/jop.2003.74.7.1038.

11. Im GI, Qureshi SA, Kenney J, Rubash HE, Shanbhag AS. Osteoblast proliferation and maturation by bisphosphonates. Biomaterials. 2004;25(18):4105-15. doi:10.1016/j.biomaterials.2003.11.024.

12. Kim HK, Kim JH, Abbas AA, Yoon TR. Alendronate enhances osteogenic differentiation of bone marrow stromal cells: a preliminary study. Clin Orthop Relat Res. 2009;467(12):3121-8. doi:10.1007/s11999-008-0409-y.

13. Fisher JE, Rogers MJ, Halasy JM, Luckman SP, Hughes DE, Masarachia PJ, et al. Alendronate mechanism of action: geranylgeraniol, an intermediate in the mevalonate pathway, prevents inhibition of osteoclast formation, bone resorption, and kinase activation in vitro. Proc Natl Acad Sci U S A. 1999;96(1):133-8.

14. Hughes DE, Wright KR, Uy HL, Sasaki A, Yoneda T, Roodman $\mathrm{GD}$, et al. Bisphosphonates promote apoptosis in murine osteoclasts in vitro and in vivo. J Bone Miner Res. 1995;10(10):147887. doi:10.1002/jbmr.5650101008.

15. Plasmans CM, Jap PH, Kuijpers W, Slooff TJ. Influence of a diphosphonate on the cellular aspect of young bone tissue. Calcif Tissue Int. 1980;32(3):247-66.

16. Plotkin LI, Weinstein RS, Parfitt AM, Roberson PK, Manolagas SC, Bellido T. Prevention of osteocyte and osteoblast apoptosis by bisphosphonates and calcitonin. J Clin Invest. 1999;104(10):1363-74. doi:10.1172/JCI6800.

17. Fromigue O, Body JJ. Bisphosphonates influence the proliferation and the maturation of normal human osteoblasts. J Endocrinol Investig. 2002;25(6):539-46.

18. Sato M, Grasser W, Endo N, Akins R, Simmons H, Thompson $\mathrm{DD}$, et al. Bisphosphonate action. Alendronate localization in rat bone and effects on osteoclast ultrastructure. J Clin Invest. 1991;88(6):2095-105. doi:10.1172/JCI115539.

19. Wang CZ, Chen SM, Chen CH, Wang CK, Wang GJ, Chang JK, et al. The effect of the local delivery of alendronate on human adipose-derived stem cell-based bone regeneration. Biomaterials. 2010;31(33):8674-83. doi:10.1016/j.biomaterials.2010.07.096.

20. Bobyn JD, Thompson R, Lim L, Pura JA, Bobyn K, Tanzer M. Local alendronic acid elution increases net periimplant bone formation: a micro-CT analysis. Clin Orthop Relat Res. 2014;472(2):687-94. doi:10.1007/s11999-013-3120-6. 
21. Tagil M, Astrand J, Westman L, Aspenberg P. Alendronate prevents collapse in mechanically loaded osteochondral grafts: a bone chamber study in rats. Acta Orthop Scand. 2004;75(6):756-61.

22. Golub LM, McNamara TF, Ryan ME, Kohut B, Blieden T, Payonk G, et al. Adjunctive treatment with subantimicrobial doses of doxycycline: effects on gingival fluid collagenase activity and attachment loss in adult periodontitis. J Clin Periodontol. 2001;28(2):146-56.

23. Walter MS, Frank MJ, Satue M, Monjo M, Ronold HJ, Lyngstadaas SP, et al. Bioactive implant surface with electrochemically bound doxycycline promotes bone formation markers in vitro and in vivo. Dent Mater. 2014;30(2):200-14. doi:10.1016/ j.dental.2013.11.006.

24. Kaur K, Sikri P. Evaluation of the effect of allograft with doxycycline versus the allograft alone in the treatment of infrabony defects: a controlled clinical and radiographical study. Dent Res J. 2013;10(2):238-46.

25. Holmes SG, Still K, Buttle DJ, Bishop NJ, Grabowski PS. Chemically modified tetracyclines act through multiple mechanisms directly on osteoclast precursors. Bone. 2004;35(2):471-8. doi:10.1016/j.bone.2004.02.028.

26. Kent ME, Rapp RP, Smith KM. Antibiotic beads and osteomyelitis: here today, what's coming tomorrow? Orthopedics. 2006;29(7):599-603.

27. Shi M, Kretlow JD, Nguyen A, Young S, Scott Baggett L, Wong $\mathrm{ME}$, et al. Antibiotic-releasing porous polymethylmethacrylate constructs for osseous space maintenance and infection control. Biomaterials. 2010;31(14):4146-56. doi:10.1016/ j.biomaterials.2010.01.112.

28. Pillai RR, Somayaji SN, Rabinovich M, Hudson MC, Gonsalves KE. Nafcillin-loaded PLGA nanoparticles for treatment of osteomyelitis. Biomed Mater. 2008;3(3):034114. doi:10.1088/17486041/3/3/034114.

29. Agarwal A, Bhattacharya HS, Srikanth G, Singh A. Comparative evaluation of decalcified freeze dried bone allograft with and without local doxycycline in non-contained human periodontal infrabony defects. J Indian Soc Periodontol. 2013;17(4):490-4. doi:10.4103/0972-124X.118322.

30. Kashi TS, Eskandarion S, Esfandyari-Manesh M, Marashi SM, Samadi N, Fatemi SM, et al. Improved drug loading and antibacterial activity of minocycline-loaded PLGA nanoparticles prepared by solid/oil/water ion pairing method. Int J Nanomedicine. 2012;7:221-34. doi:10.2147/IJN.S27709.
31. Gad HA, El-Nabarawi MA, Abd El-Hady SS. Formulation and evaluation of PLA and PLGA in situ implants containing secnidazole and/or doxycycline for treatment of periodontitis. AAPS PharmSciTech. 2008;9(3):878-84. doi:10.1208/s12249-0089126-9.

32. Chaichanasakul T, Kang B, Bezouglaia O, Aghaloo TL, Tetradis S. Diverse osteoclastogenesis of bone marrow from mandible versus long bone. J Periodontol. 2014;85(6):829-36. doi:10.1902/ jop.2013.130376.

33. Triffitt JT. Initiation and enhancement of bone formation. A review. Acta Orthop Scand. 1987;58(6):673-84.

34. Chang CY, Yamada S. Evaluation of the regenerative effect of a $25 \%$ doxycycline-loaded biodegradable membrane for guided tissue regeneration. J Periodontol. 2000;71(7):1086-93. doi:10.1902/jop.2000.71.7.1086.

35. Mackie PS, Fisher JL, Zhou H, Choong PF. Bisphosphonates regulate cell growth and gene expression in the UMR 106-01 clonal rat osteosarcoma cell line. Br J Cancer. 2001;84(7):951-8. doi:10.1054/bjoc.2000.1679.

36. Shanbhag AS. Use of bisphosphonates to improve the durability of total joint replacements. J Am Acad Orthop Surg. 2006;14(4):215-25.

37. Pihlajamaki H, Bostman O, Tynninen O, Laitinen O. Long-term tissue response to bioabsorbable poly-L-lactide and metallic screws: an experimental study. Bone. 2006;39(4):932-7. doi:10.1016/j.bone.2006.04.009.

38. Park JB. Effects of doxycycline, minocycline, and tetracycline on cell proliferation, differentiation, and protein expression in osteoprecursor cells. J Craniofac Surg. 2011;22(5):1839-42. doi:10.1097/SCS.0b013e31822e8216.

39. Diel IJ, Bergner R, Grotz KA. Adverse effects of bisphosphonates: current issues. J Support Oncol. 2007;5(10):475-82.

40. El-Amin SF, Attawia M, Lu HH, Shah AK, Chang R, Hickok NJ, et al. Integrin expression by human osteoblasts cultured on degradable polymeric materials applicable for tissue engineered bone. J Orthop Res. 2002;20(1):20-8. doi:10.1016/S07360266(01)00062-6.

41. Molteni R. Prospects and challenges of rendering tissue density in Hounsfield units for cone beam computed tomography. Oral Surg Oral Med Oral Pathol Oral Radiol. 2013;116(1):105-19. doi:10.1016/j.oooo.2013.04.013. 